\title{
The Analysis of Structural Complexity of Piano Pieces "Dedicated to Alice"
}

\author{
Junzhong Zhang \\ The Music Department in Teachers College of Eastern Liaoning University
}

\begin{abstract}
Beethoven is a famous German pianist, composer, and conductor, and he set the culmination of Western classical, created a romantic music camp precedent. The size of his music in general is very ambitious, mostly concertos, symphonies, operas and other large works, technical approach and structure used is quite complex, people are left with a deep impression. But it works, while small piano pieces, also has music research value, "dedicated to Alice" is one of the few Beethoven piano pieces. This paper focuses on creative background "dedicated to Alice," this elaborate piano works by the complexity of the analysis of the structure of this work is that it reflects the author's ideological soul to explore their musical value.
\end{abstract}

Keywords-Beethoven; Piano Pieces; "dedicated to Alice"; complex structures

Beethoven's full name is Ludwig Van • • Beethoven (Ludwig van Beethoven), born in 1770 , he is not only a famous German pianist, composer, and conductor, but also the Vienna Classical Music important representative. Beethoven grew up on the show in terms of the extraordinary musical talent, began performing on the stage since eight, in 1792, he came to Vienna, after guidance by Haydn, music, the arts have made great progress, in 1795 he published his first works. His life has a lot of well-known works, including major Symphony No. 9, 10 violin sonatas, string quartets 16,35 piano sonatas (including the 32 with a number, in addition to an opera, 2 Department of Mass, a cantata with three cantatas, as well as a large number of art songs, dance, chamber music, of which the most famous is the fifth "Destiny," the sixth "Pastoral" Ninth "Choral" and the opera "fee Dai Liao ", etc. but from the twenty-year-old he began to gradually have weakened hearing, he became deaf in his later years, but that does not make him malaise, but in the lonely life he can still be true to his" equality, liberty, fraternity "political beliefs, still adhere to music, through his own work as well as freedom of speech, to promote their own political ideology, as well as the ideal republican struggle and cry, which reflects the time the bourgeois pursuit of democracy and against the feudal autocratic conviction and enthusiasm. Bedouin Finland is known as Le Sacre music, which set the culmination of Western classical, romantic music camp created a precedent, his music works are influenced by eighteenthcentury German Sturm und Drang movement, the performance has very distinctive personality that relates to the genre and it is also very widely, greatly improves the expressive piano, grand scale, clever technical approach, and complex but the clarity of the structure, and to the people it left a deep impression. Beethoven's works both on the development of world music and had a great impact, which greatly promoted the development and progress of music history.

\section{Creating Background Of "Dedicated To Alice"}

"To Alice" is one of Beethoven's piano works in their forties when creation, as long as have little understanding to Beethoven we'll know, "dedicated to Alice" and his other works of Beethoven styles are very different, a fate by the throat even spiritual giants would create such a beautiful soft ballad, which is unbelievable. "To Alice" is in 1867, the German musician Noel is writing a biography of Beethoven again when students Therese Malfatti relics found in the manuscript, so Beethoven was not to be published during his lifetime. About this song's creating background there are many arguments, one of which most people accept the argument is "dedicated to Alice" is created of Beethoven for soprano and it is ne of his creation, the soprano - Roker named Elizabeth, is famous tenor Joseph • August - Roker sister. Fourteen-year-old Elizabeth in 1807 with his brother Joseph came to follow international music metropolis Vienna, she wonderfully encounters Elizabeth and became a friend of Beethoven, and she is one of the few close friends of Beethoven. Later, a friend of Elizabeth and Beethoven's married. Alice is Elizabeth's nickname, it appeared only a woman named Alice in Beethoven's life, and in the creation of this song he and Elizabeth also maintained a good friendship. So obviously, this song made for Elizabeth by Beethoven. Some people say that this song is the theme of Beethoven I expressing affection for Alice, there are those who say that the theme of this song is the description of a beautiful girl image. Overall, these two arguments are contradictory and there is no conflict and not adjustable. Beethoven had a really rough life, nor marry a girl or have a family, but he is always in pursuit, and eager for the arrival of sweet love, "dedicated to Alice" will bear a romantic feeling inside.

\section{Complexity Structure Of "Dedicated To Alice"}

From music by Beethoven summary and analysis, we can see that his work is of very grand scale, technical approach is used in the creation of very complex, but the structure is very clear. But his piano pieces work, especially 
for "dedicated to Alice," it has relatively short length, creative approach is quite simple, but the structure is not very clear, flexible terms from the whole song are complex. Here we mainly analyze and explore the complexity of its structure.

This is the first dapper piano pieces divided into five paragraphs, respectively: $\mathrm{A}+\mathrm{B}+\mathrm{A} 1+\mathrm{C}+\mathrm{A} 2$. On the surface, this is the creation of a piano Rondo typical style, where the main part A has appeared three times, between the main portion and the main portion and they are inserted into the B and C of the Ministry, recurring embodied in Part A of this the basic theme song, B and C are inserted Ministry and also took shape with the main part of different music image. Music theme cordial, simple, right heroine is both beautiful and gentle and beautiful image summarized description, creator of gentle words seemed to have a thousand words to tell her. In the machine-specific narrative style roundabout way, it will be interspersed with music theme organic part linked together, alternating hands broken chords playing, it seems to be the creator of the girls in intimate conversation with, so this song is full of romantic atmosphere and fun, which highlights the performance of the entire song in contrast to the image and character. If part of the calculation is not repeated, the main portion of a total twenty-two music section to $8 / 3$ beat rhythm on a minor appears, showing the internal structure of reproducing the characteristics of a single trilogy style, rendering part consists of two four section parallel phrases constitute a total of eight sections, at the end of a minor's statements it makes music for us to start showing a slim, smart, intimate narrative tone. Go to the middle part of the relationship between a minor major $\mathrm{C}$ major, which is part of the only six sections, but in rendering it has done little to expand the basis of performance on the part of the topic, to continue into the connection before reproduction, and reproduction section to prepare is a minor case of tone $\mathrm{E}$, reproducing section back to a minor, so the cycle repeats. Then Part B in F major subordinate direction statements is a structure similar to the music segment, a total of eight sections using tactics plus stacked into eight sections, forming a connection transitional paragraph. This part of the music with a sense of color is very outset based on a F major, in this part of emotional expression, the main portion and a gentle warmth in stark contrast to the author's emotions and tend to become clear and open style, people feel like being in the sky and the earth in broad, even the air becomes fresh and cute together, while playing the part of $\mathrm{B}$, the left hand is converted into Alberti bass accompaniment style shape, the right hand broke through the melodic rhythm section A the sharing pattern, so that the rhythm of the music becomes rich, enrich themselves, plus the echo, appoggiatura is still dotted rhythm of use and makes this part of the music very smooth and gorgeous, to the audience it created a warm, gracious, and full of fun music image. Part B has emerged after the end of each section of Part A and it is removed completely repeatedly reproduced, in general, there has been continued figurations at the end of the main part and it indicates that this music is about to end, but the Lord continued figurations continue playing took place during the new changes, the music in $\mathrm{C}$ major on the basis of shows a very active CLS phrases, vivid depiction of a dignified image of the girl outside, yet it is still lively, cheerful and naive endowments. In the second part of the insert part $\mathrm{C}$, the main part of the song is beautiful, gentle, smart and confident $\mathrm{B}$ plug part, innocent, lively, into a firm and serious, the audience listening to the process will feel like a vicissitudes of life of the elderly against lament a heart full of innocence and vitality issued. Further naturally leads to the emergence of the third main portion, relating to the reproduction of the A portion of the first time, after the reproduction of the original part ah trilogy end it is as an alternate configuration of a functional portion changes, it is the second part $\mathrm{C}$ which is inserted to form the role of the Ministry of contrast, this structural arrangement for the audience arranged an unexpected effect, making it easier to attract the audience's attention. In addition, the reproduction of part A third is also with the previous theme echoes to make it back to vibrant, innocent and wonderful fun to go to lively rhythms when the music ended.

\section{The IdeA Of The Soul Embodied In "To AlicE" MUSIC}

"To Alice" is as one of the world's most popular classical piano pieces, and it has relatively unique creative approach, as long as we have little understanding about Beethoven, we will find this song has very different writing style with his other works. Maybe we can not imagine a spirit capable of strangling the throat fate would write such a gentle giant lingering ditty. But perhaps it is precisely because of this song in sharp contrast to the huge difference between the formation of other works of Beethoven, we have a more profound understanding of Beethoven, of course, this piece of art charm left a very impressed impression to the people.

Beethoven set a warm and rustic theme in the song "dedicated to Alice". In fact, both "dedicated to Alice" is depicting the image of a beautiful girl or just expressing a deep love of Beethoven, it ultimately reflects the Beethoven praise for all the good women, and for the noble love pursuit and beliefs. In the first half of this song, Beethoven uses the beautiful yet smooth notes of gentle, makes description of the image of a beautiful girl, it is melody and soft, like a kind of intimate conversation between friends, and the girls' purity and innocence are revealed, people are likely to generate association. Soft melodies serene is yet comfortable, so that people feel that everything this world is so beautiful, the picture is so moving, everything around is colorful, just like when they are in the mood of love, warm, soft, people are intoxicated. This part emerges sixth times in the whole song, and left a very deep sound to the audience. By the second half of alternating left and right hand broken chords he played, the audience as if produce a romantic intimate conversation between lovers delight. Part B episode is based on the $\mathrm{F}$ major, feelings clear, cheerful, Part C after the episode is used more chords, so the 
atmosphere undergone great transformation, it is stable, serious, as if in meditation, but a little sad, as if a resume of the elderly are facing a life filled with pure hearts lament life. C segment Finally, composed music to triplet phrase, emotional expression gradually warm up, after a downward chromatic transition, and it is finally back to the A section, so that people return again to be filled with a lively, vibrant taste, the final song in the gentle atmosphere of the beautiful painting has a perfect ending. The whole song is melody and moving, while fast-paced slowly, notes changes constantly occur, people's mood with the melody are sometimes happy, sometimes sad, repeated alternately, to people's hearts have tremendous impact. "To Alice" is undoubtedly a success, and it has been the people's favorite to become the world's music industry and occupies an important position in both classic piano works.

\section{SUMMARIZES THE LANGUAGE}

In general, the composer for piano arrangements of works on the structure and content often requires him to express in the song, which is adapted, Beethoven's piano pieces song dapper course is no exception. Overall, "dedicated to Alice," works as an ordinary piano solo songs, it has a beautiful melody and comfortable brisk pace, playing techniques is relatively easy to grasp, at the end of the shift over the insert section by chord type statements express the heart of the firm, and it has been a good artistic effect, it is loved by the people, the complexity of its structure surprisingly also further increased the value of music study this work.

\section{REFERENCES}

[1] Gao Fuxiao, form musical works to analyze the connotation of experience - to Beethoven's "Piano Sonata" (Op.106) The third movement is a case study [J] Huangzhong - Wuhan Conservatory of Music .2012 (04): 74-75

[2] Huang Venqu, Dedicated to Alice "analysis [J] Arts .2008 (03): 54-54

[3] Wang Tao, Shelin decrypt to musical works of Beethoven " [J] Art hundred .2010 (06): 12-13

[4] Cui Qiangao, Performance in the second creation of musical diversification - in different versions of the piano song "dedicated to Alice," for example [J] art criticism .2012 (06): 46-48.

[5] Zhangchi, From three Piano Works to explore Beethoven's "c minor Complex" [J] Musical Arts .2012 (01): 87-88

[6] Tang Shanshan "dedicated to Alice" sound analysis [J] Music Grand .2013 (05): 52-53 [7]Wang Haibo, Perfect interpretation of the spirit and wisdom of - Buchbinder interpretation of Beethoven's music [J] People's Music (review version) .2013 (03): 16-17.

[8] Liyue Ping, development and innovation Beethoven sonata for symphony divertimento [J] Sichuan drama .2013 (01): 39-40

[9] Zhang Hui Chao, Zhang Ruirong. interpretation of "Heroes" [J] sound .2012 Yellow River (11) from Beethoven's experience: 53-54

[10] Ma Yan, musical identify the main factors - from Beethoven's "dedicated to Alice," musical form controversy Speaking [J] Qujing Teachers College .2010 (03): 126-127. 